\title{
Research allocations: Subjective factors often influence outlays
}

Published at www.cmaj.ca on Apr. 22

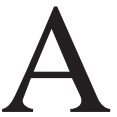
llocating health research money is no easy task: No matter how the funds are divvied up, many people won't be happy.

Many Canadians also assume that allocations are based on concrete factors or firm policies aimed at redressing specific health problems or diseases. Yet, the reality is that the rationale for funding allocations has been little examined.

As Jeremy Shiffman, an associate professor of public administration at Syracuse University in New York who researches the political dynamics of health and policy-making, notes: "We actually know much less than we think about the factors that shape resource allocations in public health."

In Canada, the Canadian Institutes of Health Research (CIHR) is responsible for allocating roughly $\$ 1$ billion in public money for health research annually. It spends that money in four "pillar" areas: biomedical; clinical; health systems services, and social, cultural, environmental and population health. The bulk of the money is divvied up in general research grant competitions, but some of it is allocated through competitions administered by its 13 interdisciplinary networks, called institutes, that cover everything from aboriginal peoples' health and aging to cancer research, infection and immunity, neurosciences, mental health and addiction and population and public health.

In general terms, the CIHR has repeatedly stated that it allocates about $70 \%$ of all its grants issue for basic, curiosity-driven, discovery-based research and about 30\% for research in strategic, or targeted, areas determined by such factors as public health need.

CIHR says its grants are awarded by peer review, with the winners chosen on the basis of "excellence," in terms of

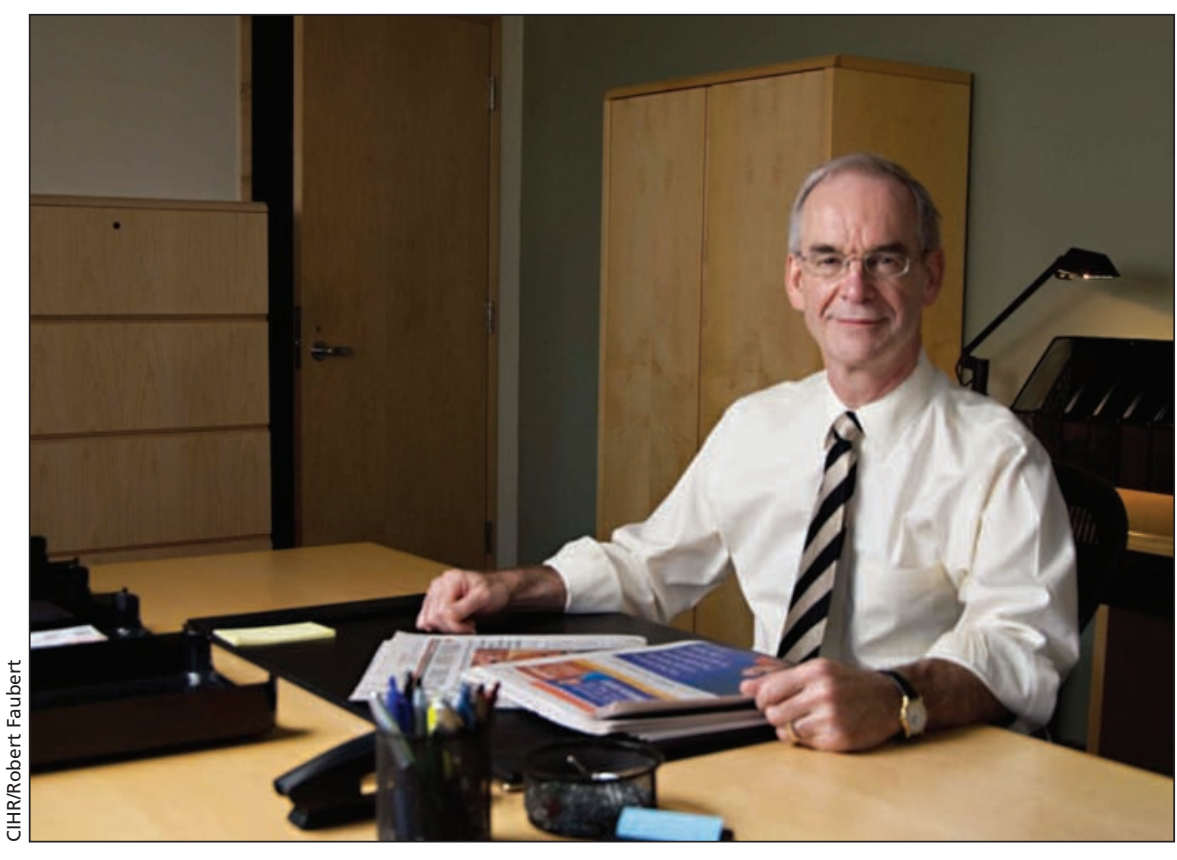

Comparing the value of criteria for establishing strategic programs can be problematic, says Canadian Institutes of Health Research Vice-President of Research Pierre Chartrand.

originality, creativity, scientific and ethical soundness and the probability of research having a significant impact. "This enables us to maintain a strong and vibrant research community for us to draw upon," says Pierre Chartrand, vice-president of research at CIHR.

Yet, that model yields research outlays that are often skewed, even within the broad spectrum of basic research, toward certain disciplines or diseases, whether because of national scientific capability, interest or even historical habit.

CIHR has argued that it offsets such potential biases with periodic reviews of peer review committee system, as well as investments in strategic, or targeted, research.

Strategic programs, whether offered by an institute or the CIHR's general council, are meant to fill in the gaps. At the institute level, health priorities are evaluated by advisory boards composed of people from the private, public and nonprofit sectors. Factors that can influence whether a strategic program is developed include such considerations as the burden of a disease on patients, its effect on the health care system, its impact on the economy and the likelihood that research will produce results.

"There's a need to consider if there is something we can do about it [a health problem]," says Chartrand. "Can we have a breakthrough and make a difference?"

Material factors such as the mortality and morbidity burdens of a disease can play a large role in how much attention and funding it receives within strategic programming. But these factors are inherently subjective, which can make setting health priorities challenging.

"It is very difficult to evaluate or compare criteria," says Chartrand. "Mortality for some people is the most important. Then there are others who think it's about quality of life. To some extent, these are value judgments." 
There are also other factors, beyond health burdens, that affect which diseases receive the most attention, such as the political dynamics of the day. "Many decisions and many allocations are heavily politically infused, and one could argue that, in a democratic society, that makes sense," says Shiffman.

This may be part of the reason why arthritis - which, unlike AIDS or cancer or even rare genetic diseases, has never been a hot political topic — was at the bottom of the list for research funding.

"The reality is that if a large part of the community is moved by a particular chronic illness that is more visible, and in fact may kill you, the political environment is such that we must respond to that sentiment," says Steven McNair, president and chief executive officer of the Arthritis Society. "That puts the onus on disease groups like us to better communicate the impact of diseases like diabetes."

According to a section of CIHR's website called "Your Health Research Dollars at Work," the area of research that received the most funding, at \$263.5 million, in 2008/09 was infectious diseases (www.cihr-irsc.gc.ca/e 139924.html). Genetic research was next, $\$ 244.1$ million, followed by cancer research, $\$ 138$ million. The bottom three of the 13 research areas were diabetes, \$35.4 million; Alzheimer disease, \$22.1 million; and arthritis \$21.6 million (see sidebar).

The National Institutes of Health
(NIH) in the United States, by contrast, spent more than twice as much in 2009 on genetic research, US\$8.95 billion, than on infectious diseases research, US $\$ 4.15$ billion. Investment in cancer research, US\$6.75 billion, also exceeded money allocated to research in infectious

.mrc.ac.uk/Utilities/Documentrecord/ind ex.htm?d=MRC006563).

Some argue that new approaches to dividing the research pie should be investigated.

A better approach to allocating funding for health research, as opposed to dividing resources between institutes associated with particular diseases, would be to fund research that explores what different diseases have in common, says Marco Di Buono, director of research at the Heart and Stroke Foundation. "There is a bit of a bottleneck and maybe that bottleneck could be alleviated by encouraging more collaboration and by getting people to think more about common goals and common outcomes instead of just disease silos."

In the end, however, allocating money for research will always be a subjective activity open to criticism, and the same questions are likely to be asked again and again.

"How do you set your prior-

diseases. Like CIHR, however, the NIH spent much more in these research areas than in diabetes, US\$1.15 billion; Alzheimer disease, US\$534 million; and arthritis, US\$311 million (report.nih.gov /rcdc/categories/Default.aspx).

Research into infections and immunity was also a funding priority for the United Kingdom's Medical Research Council, which spent $£ 126.6$ million in the area, though not as high a priority as research in molecular and cellular medicine, £252.2 million, or neurosciences and mental health, £141.5 million (www ities?" asks Dr. Mark Greenwald, chair of the scientific and medical advisory committee for the Asthma Society of Canada. "Do you set them politically? Do you set them economically? Do you set them by who is the squeakiest wheel?" - Roger Collier, CMAJ

DOI:10.1503/cmaj.109-3238

First of a series on dividing the research pie 